\title{
Insectes Sociaux best paper 2018
}

\author{
B. Michael ${ }^{1}$
}

๑ International Union for the Study of Social Insects (IUSSI) 2019

Paul J. Davison and Jeremy Field have received the prize for the best paper published in Insectes Sociaux in 2018 for their paper "Environmental barriers to sociality in an obligate eusocial sweat bee", which appeared in the October 2018 issue of Insectes Sociaux, volume 65.

Davison and Field (2018) tested the effect of environment on expression of eusociality by transplanting nests of an obligately eusocial sweat bee, Lasioglossum malachurum, from their native habitat in southeastern England to a northern site with a much shorter growing season. Their core hypothesis was that length of growing season and its corresponding effect on colony longevity are limiting factors for sociality, with longer growing seasons being required for completion of enough brood cycles to encompass a eusocial strategy. This was an extraordinarily challenging experiment to execute, as it involved excavation and transport of soil containing potentially fragile nest structures. Their results clearly support their hypothesis and help us to understand the conditions under which eusociality can evolve.

Paul Davison received a MZool degree from the Bangor University and then his Ph.D. from the University of Sussex, working with Prof. Jeremy Field on "Social polymorphism and social behaviour in sweat bees".
Jeremy Field is now a Professor of Evolutionary Biology at the University of Exeter. Prof. Field's lab focuses on behavioral plasticity and the evolutionary mechanisms underlying social behavior. Prof. Field and his students work on primitively eusocial wasps and bees.

The editors and editorial board of Insectes Sociaux selected the recipient of this award. The board consists of prominent scientists from leading universities with global representation. Insectes Sociaux publishes original scientific studies and review articles about social arthropods.

Michael Breed

Editor-in-Chief

Insectes Sociaux

\section{Reference}

Davison PJ, Field J (2018) Environmental barriers to sociality in an obligate eusocial sweat bee. Insectes Soc 65(4):549-559. https:// doi.org/10.1007/s00040-018-0642-7
B. Michael

Michael.Breed@colorado.edu

1 University of Colorado Boulder, Boulder, USA 